\title{
The Problems and Countermeasures of Overseas Warehouse Construction in China under the Situation of "the Belt and Road" Initiative
}

\author{
Yunkai Zhai ${ }^{1}$, Ruixia Zhang ${ }^{1}$ \\ Management Engineering Department, Zhengzhou University, Henan Province, China \\ 873567861@qq.com
}

Keywords: The Belt and Road, oversea location, problems, countermeasures

\begin{abstract}
1. INTRODUCTIONTHE NECESSITY OF OVERSEAS WAREHOUSE CONSTRUCTION IN CHINA UNDER THE BACKGROUND OF ONE BELT AND ONE ROA
\end{abstract}

Abstract: With the implementation of the "zone along the way" strategy, the economic and cultural exchanges between China and countries along the Belt and Road have become increasingly close. More and more companies are building overseas warehouses in countries along the route. This paper analyzes the current situation of overseas warehouse construction, the specific problems existing in overseas warehouse construction, and the related countermeasures.

Road" can effectively solve these problems. Overseas warehouses can not only greatly reduce the cost of

Since the development strategy of "the Belt and Road"has been proposed, the economic and cultural trade between China and countries along the belt and road has become more and more frequent. "the Belt and Road" construction adhere to the business, sharing, to build principles, Uphold the spirit of open regional cooperation. The construction of overseas warehouses will help China to expand its trade along the country along the road, strengthen economic and cultural exchanges, and realize the mutual benefit and win-win situation (Sanfeng, Zhang,1999). The need for overseas warehouse construction is reflected in the following three points:

\subsection{Enhance the international competitiveness of industries and products}

First, by building overseas warehouses, the logistics cost of goods can be greatly reduced. As cross-border electric business with small batch, multi-batch and other characteristics, cross-border electricity business can be based on market volume, the bulk of goods shipped to overseas warehouses, reduce transport, customs clearance, commodity inspection and other frequencies, significantly reduce the cost of the above links. The Bulk scale can effectively reduce the risk in all aspects of logistics, to achieve a substantial reduction in crossborder electricity business logistics costs

1.2 Ensure the healthy development of China's crossborder electricity business

In recent years, the rapid development of crossborder e-commerce, trading volume increased significantly, but also to cross-border logistics has brought a lot of challenges. With the increasing number of overseas orders, burst warehouse, backlog, logistics delays and other problems occur frequently. Customer satisfaction fell sharply. But the establishment of overseas warehouses by countries along the "the Belt and logistics, so that the process of returning goods more efficient and convenient, but also to improve the profitability of individual goods, stablesupply chain to increase sales, expand sales category, and sales" localization."

\subsection{Strengthen China's economic and trade cooperation with the countries along the line of the Belt and Road}

Under the "the Belt and Road" strategy, the policy communication is conducive to the breaking of the logistics industry's overseas investment, complete regulations and non-complete regulatory barriers; The road unicom will greatly promote China and the country's transport infrastructure and communications connectivity. Trade flow and prosperity will lead to a surge of goods flow, for China's logistics industry sustainable development to create a strong overseas market demand; The "two Banks and one gold" will provide strong financing support and financial risk protection guarantee for China's overseas layout.

\section{CURRENT SITUATION OF CHINA 'S CROSS - BORDER LOGISTICS OVERSEAS WAREHOUSE DEVELOPMENT}

\subsection{The number of rapid growth}

In recent years, with the development of the development strategy, China's rapid development of cross-border electricity business, cross-border logistics, the rapid growth in the number of overseas positions. According to China's logistics and procurement network data show that during 2013-2016 period, China's overseas warehouse continued to grow, from more than 50 in November 2013 increased to more than 500 in November 2016, with an average annual growth rate of 77\% (Xiaoyan Zhang, 2017). Specifically, Jingdong, Alibaba and Vipshop will have to carry out in-depth cross-border e-commerce, the establishment of the rapid increase in the number of logistics positions overseas.In addition, China's logistics enterprises such as shunfeng 
and yunda have also been actively involved in overseas warehouse markets and have set up overseas warehouses around the world.

\subsection{Mainly concentrated in developed countries}

Developed countries have a high penetration rate and rapid development of e-commerce market, as a result, At present, our export enterprises are mainly concentrated in the United States, Germany, Britain, Japan, Australia and other developed countries. Developed countries, high penetration rate of network equipment and ecommerce market is developing rapidly, thus, the current export enterprises in China cross-border overseas warehouses mainly concentrated in the United States, Germany, Britain, Japan, Australia and other developed countries. However, with the evelopment of this strategy to promote, China and the country's along the line is increasingly close, more and more companies and companies to focus on these countries, ready to establish overseas positions in these countries. many companies have begun to try to establish in these countries Overseas warehouses, in the near future, overseas warehouses may be concentrated in these countries a large number of appear.

\subsection{Great development advantage}

At present, with "the Belt and Road" strategy in depth, our government is actively promoting and vigorously guides the construction and development of overseas warehouses.

There are several advantages to building overseas warehouses in the countries along "the the Belt and Road”. First, The establishment of overseas warehouses greatly reduces the international logistics and transport time to protect the safety of goods transport process; second, to a certain extent, it reduces the logistics costs; Thirdly, it makes the return process more efficient and convenient, and is conducive to improving the consumer's terminal experience; Increase work The establishment of overseas warehouses; At last, it adds jobs and increases employment.

\section{FORMPROBLEMS EXISTING IN THE CONSTRUCTION OF OVERSEAS WAREHOUSE IN CHINA}

Overseas warehouse is essentially a capital and technology-intensive industries, need to continue to invest funds and time to improve. Without the rapid accumulation of venture capital and its own size, China's overseas warehouses are prone to stagnation, and not all commodities are suitable for overseas warehouses. With overseas positions, it does not mean that there is a crossborder electricity business solution.

\subsection{A risk of clearance}

The biggest difference between cross-border logistics and domestic logistics is that it needs to pass two customs checkpoints: export customs and destination country customs. In the export of cross-border ecommerce, the key to logistics lies in the customs of destination country, In the process of customs clearance, customs buckles are frequently checked, extended delivery times, and may even result in buyers' complaints or refusal of payment.

\subsection{Inventory pressure}

Overseas warehouse need to stock up in advance, as long as there is stock there is the risk of unmarketable, the small and medium-sized sellers, for the use of big data do not have advantage, for goods sold well and unsalable and cannot make accurate judgment, as a result, they are in stock, it is difficult to carry on the reasonable configuration according to the market demand, this will increase the enterprise's inventory cost. If you can not grasp the sales of the product, then the proposed start not too much delivery, starting part of the product, try to sell, through sales analysis, and then a lot of added. For the handling of slow-moving products, in general, will not be shipped back to China, otherwise it will become an import problem. Therefore, in the event of slow sales, it is necessary through a variety of promotional means to dispose these poor sales as far as possible, Which in turn will cause some loss to the enterprise.

\subsection{High construction costs}

Construction of overseas warehouses need to invest a lot of capital, including land rent, building materials purchase, warehouse design and construction, hardware and software facilities, equipment procurement, installation and commissioning and a variety of labor costs. In some developed countries, these costs far exceed those of China. The company's chief executive, zeng bibo, has pointed out that an overseas warehouse of about 3,000 square meters in the United States needs to invest millions of dollars, with labor costs accounting for about 30 percent to 40 percent. The cost factor should be fully taken into account in the construction of overseas warehouse (Yuan Meng,2017).

\subsection{Related policy and legal issues.}

The differences in legal policies in different countries will directly affect the difficulty and cost of overseas warehouse construction. For example, in Europe and the United States market, the international logistics program policy continues to improve, overseas warehouse gradually mature, and easy to operate.In addition, due to the high import tariff, the development of local express industry and the distribution of the delayed node, Russia has been focusing on factors such as large and mediumsized cities, resulting in the predicament of its overseas warehouse layout. On the contrary, the development of the regional express industry is approaching maturity in the European and American countries, which will be standard for overseas warehouse (Jiangong Wu, Hui Zhang,2016). The European and American buyers have a unified understanding of overseas warehouses. Their overseas warehouse management is more standardized and the comprehensive talent quality is higher, thus promoting the construction and development of overseas warehouses in the region. 


\section{FORMCOUNTERMEASURES AND SUGGESTIONS}

\subsection{Using border positions}

For a market that is difficult to clear customs, consider adopting the frontier warehouse. For some market, while the market is big, but because of higher import tariff, domestic express industry development lag, the factors such as node layout concentrated in large and medium-sized cities, the current Chinese electricity USES mostly overseas warehouse goods "gray clearance". This puts a potential risk on the development of overseas warehouses. By contrast, the border bunker is still in China, and the goods are still under control and the labor costs are relatively low.

By contrast, the border bunker is still in China, and the goods are still under control and the labor costs are relatively low.

In addition, as the goods are still in the territory, no customs clearance is required. When the customer receives the order, the goods are cleared from the border, and the security of the goods is guaranteed. Therefore, for goods with low value and light weight, it is more suitable for the model of frontier warehouse.

\subsection{Open up overseas virtual warehouse}

The overseas virtual warehouse is to turn the inventory of offline stores into the inventory of ecommerce exporters. Construction of overseas virtual warehouse can be the nearest delivery and speed up the delivery speed; The construction of overseas virtual warehouse can be the nearest delivery, speed up the delivery rate; the goods inventory scattered in the line under the store, you can reduce the storage costs; to achieve cross-border electricity business O2O, line stores can provide customers more "trial" experience. Offline store can have multiple functions combined, namely the provision of procurement services to small local wholesalers, the second is to help sellers to showcase the brand to provide goods and retail functions, providing localization services for buyers and experiential consumption, the third is to help sellers Processing inventory(Guizhi Pan, 2015). The general purpose is to develop a variety of sales channels for the seller to solve the problem of inventory, improve inventory turnover, and can provide local services, so that cross-border electricity business can be closer to the local market.

\subsection{Strengthen big data analysis}

Compared with the traditional international trade model, the current cross-border e-commerce has the advantages of big data analysis. Through the analysis of large data, we can accurately analyze the purchase behavior of consumers, such as the age, income level, consumption habits, purchase frequency, purchase quantity, purchase time and so on. This will be able to more accurate stocking and replenishment, reduce inventory costs, improve the efficiency of overseas warehouse management, speed up the flow of funds.

\subsection{Cooperate with local tax solutions company}

The rapid growth of China's cross-border exports has hit local businesses overseas, and since 2014, overseas governments have tightened regulations on goods from China's online exports. In the past, foreign governments have been lax in regulating cross-border e-commerce, but now European government departments have stepped up supervision of cross-border e-commerce in China, including customs clearance, tax laws and quality inspection. With the increasing supervision of foreign governments, cross-border e-commerce companies are not very familiar with each country's policies. Overseas warehouse, therefore, can consider to operating company with local agents and tax solutions company cooperation, for the Chinese merchants to provide agency operations, warehousing, customs clearance and tax services, such as three-dimensional, package.

\section{CONCLUSIONS}

At this stage, Chinese companies put the focus of the layout in overseas markets on countries along the "the Belt and Road", hoping to rely on "cross-border electricity supplier warehouse + overseas" business model, opening up a Silk Road Online Internet age. But logistics timeliness and localization problems are still a bottleneck for the development of cross-border ecommerce. Although overseas warehouse can solve the problem of cross-border e-commerce logistics to some extent, it also sees its risks through analysis. Therefore, the overseas warehouse model should take note of the development of emerging markets, strengthen and deepen cooperation with local enterprises, and explore O2O business model, using big data to improve turnover rate, multi-level and multi-angle coordination and cooperation to promote the sustainable development of cross-border e-commerce.

\section{REFERENCES}

[1] Bin Tang ,2016. "Nation along the way" strategy under the background of China's overseas warehouse construction of the necessity, China Management Information.19 (18), pp,133-134. [2] Guizhi Pan, 2015.Overseas warehouse construction and cross-border electric business logistics new model exploration, Logistics Technology and Application.20 (09), pp.130-133.

[3] Jiangong Wu, Hui Zhang, 2016.Technology of China's Overseas Warehouse Construction under the Situation of "One Way”, Management Manager, 27, p.261.

[4] Xiaoyan Zhang, 2017. There are some problems in the development of cross-border logistics overseas warehouse and the countermeasures, Foreign Trade Practice .336 (01), pp.8487.

[5] Yuan Meng, 2017.Study on the Construction of Overseas Warehouse in the Context of Cross-border Electric Business and Its Development Countermeasures. Science and Technology Innovation and Productivity. 276 (01), pp. 30-33. 